\title{
A Phase I Trial of Imatinib in combination with mFOLFOX6- \\ Bevacizumab in Patients with Advanced Colorectal Cancer
}

M Michael (MBBS (Hons), BSc(Hons), FRACP, MD), ${ }^{1, *}$

J. Zalcberg (MBBS, PhD FRACP), ${ }^{1}$

$P$ Gibbs (MBBS, MD, FRACP), ${ }^{2}$

L Lipton (MBBS, FRACP, PhD), ${ }^{2,3}$

$M$ Gouillou, MSc, ${ }^{4}$

M Jefford (MBBS, PhD, FRACP), ${ }^{1}$

G McArthur (MBBS PhD FRACP), ${ }^{1}$

M Copeman, DPhil, MRCP, FRACP, 5

K Lynch, (MBBS, B Med Sci FFPM) ${ }^{6}$

NC Tebbutt (BM BCh, FRACP, PhD), ${ }^{7}$

1. Division of Cancer Medicine, Peter MacCallum Cancer Centre, Locked Bag 1, A'Beckett St, Victoria, 8006, Australia

2. Dept Medical Oncology, Royal Melbourne Hospital, Grattan Street Parkville VIC 3050

3. Dept Medical Oncology, Western Hospital, Gordon St, Footscray, Victoria, Australia

4. Centre for Biostatistics \& Clinical Trials, Peter MacCallum Cancer Centre, Locked Bag 1, A'Beckett St, Victoria, 8006, Australia

5. Novartis Pharmacicals, Australia, Pty Ltd, 54 Waterloo Rd, North Ryde, New South Wales, Australia

6. Celgene Australia, (ex-employee Novartis Pharmacicals, Australia) ; Level 7, 607 St Kilda Road, Melbourne, 3004, Australia

7. Dept Medical Oncology, Austin Health, Studley Rd, 145 Studley Road Heidelberg VIC 3084, Australia

\section{* Corresponding Author:}

Assoc. Prof. M Michael, MBBS (Hons), BSc(Hons), MD, FRACP

Consultant Medical Oncologist, Division of Cancer Medicine,

Head GI Medical Oncology Unit,

Director Upper GI Oncology Service

Peter MacCallum Cancer Centre

Locked Bag 1, A'Beckett St, Victoria, 8006, Australia

Telephone: +61-3-9656-1159

Facsimilie: +61-3-9656-1408

Michael.Michael@petermac.org

Key Words: Imatinib, Platelet-derived growth factor, Tumoral interstitial hypertension. Colorectal cancer, FOLFOX, Bevacizumab 


\begin{abstract}
Purpose: PDGFR inhibition by reducing tumoral interstitial fluid pressure might increase the efficacy of chemotherapy. Imatinib inhibits PDGFR kinase activity at therapeutically relevant doses. This phase I study aimed to assess the MTD of imatinib in combination with mFOLFOX6-bevacizumab in patients with advanced colorectal cancer, and to identify PK interactions and toxicities. Methods: Eligible patients had measurable disease, and adequate organ function. On day -14 , patients commenced imatinib daily plus bevacizumab (5mg/kg/2 weekly). Two weeks later (day 1) patients were also treated with full dose mFOLFOX6-bevacizumab for 12 cycles. Blood samples were taken for PK. DLTs defined in the first 6 weeks. Standard dose escalation of imatinib, with 3 patient cohorts: planned dose levels (DL): DL1; 400 mg, DL2; 600 mg, DL3; 800 mg daily.
\end{abstract}

Results: 10 patients enrolled. DL1 3 patients, DL2 7 patients. DLTs observed in 3 of 6 patients in DL2: febrile neutropenia (2); Grade 3 infection \& Grade 4 neutropenia (1). Neutropenia was most frequent AEs: Grade $3 / 4$ in $>60 \%$ of patients overall. In DL2 pts, imatinib clearance was reduced postchemotherapy $(\mathrm{P}<0.05)$. Oxaliplatin and 5FU PK unchanged by imatinib.

Conclusions: MTD was imatinib 400mg plus full dose mFOLFOXbevacizumab. Dose escalation of imatinib limited by neutropenia. Further study is warranted as imatinib can be delivered at levels that inhibit PDGFR. 


\section{INTRODUCTION}

Tumour progression requires concomitant angiogenesis, through endothelial cell recruitment/proliferation, driven in part by vascular endothelial growth factor (VEGF). The establishment of a supporting pericyte network to stabilise the capillary wall is also required; driven at least in part by plateletderived growth factor receptor- $\beta$ (PDGFR- $\beta$ ) signalling.[14] PDGFR- $\beta$ is expressed in tumoural pericytes, endothelial cells and malignant cells including colon cancer.[44] The binding of its ligands (PGDF-BB) directly

promotes tumor growth and stimulates angiogenesis through increasing VEGF expression.[5, 24, 35]

Tumoural blood vessels have sparse pericyte coverage and are functionally leaky leading to an elevation of interstitial fluid pressure (IFP) or tumoural interstitial hypertension (TIH).[38] $\mathrm{TIH}$ may limit drug uptake into tumours through the reduction of the hydrostatic gradient, from capillary to tissues.[18] Modulation of tumoural angiogenesis and TIH may enhance tumoural drug exposure, improving chemotherapy efficacy. As PDGFR- $\beta$ is intimately involved in tumoural angiogenesis and IFP control, it provides a potential target for modulation of both processes.

Imatinib, through inhibition of PDGFR- $\beta$ has significant effects upon tumoural microvasculature. In preclinical models imatinib exposure has been reported to induce impaired endothelial viability, decreased IFP and thus increases the interstitial transcapillary transport of solutes.[34, 42] It also increases the tumoural uptake and anti-tumor effects of cytotoxics.[30, 33] Based on these data imatinib has been combined with cytotoxics in clinical trials. $[1,16,25,37,45]$ 
The combined effect of treatment with PDGF and VEGF inhibitors may further lower tumoural IFP. Preclinical studies have confirmed the cooperative effects of imatinib in combination with VEGF inhibitors, including the antiVEGF monoclonal antibody bevacizumab.[4, 20]

The treatment of colorectal cancer (CRC) has reached a plateau in efficacy. The most active regimens based on oxaliplatin-5FU (FOLFOX) or irinotecan-5FU with biological agents (bevacizumab or the epidermal growth factor receptor antagonists), result in median survivals greater than 20 months.[8, 17] Therefore we have investigated the combination of imatinib with mFOLFOX6-bevacizumab in advanced CRC. The aims of this trial were to: (i) define the MTD of dose escalated imatinib plus full dose mFOLFOX6bevacizumab, (ii) define the toxicity and potential pharmacokinetic (PK) interactions of the combination. An exploratory aim was to evaluate the efficacy of the combination. 


\section{PATIENTS AND METHODS}

This was a Phase I, dose escalation trial of imatinib plus mFOLFOX6bevacizumab across four oncology centres within the Cancer Trials Australia consortium (Peter MacCallum Cancer Centre, Austin Health, Royal Melbourne and Western Hospitals).

\section{ELIGIBILITY}

Eligible patients met the following criteria: (1) histologically confirmed metastatic CRC, fit for first-line chemotherapy combined with bevacizumab, (2) measurable, or evaluable disease (RECIST criteria),[41] (3) ECOG performance status 0 or 1, (4) Adequate organ function: (a) Bone marrow: Platelets $\geq 100 \times 10^{9} / \mathrm{L}$, Neutrophils $\geq 1.5 \times 10^{9} / \mathrm{L}$, (b) Renal function: Creatinine clearance $\geq 50 \mathrm{ml} / \mathrm{min}$; (c) Hepatic function: Serum total bilirubin $<1.5 x$ upper limit of normal (ULN), Alanine aminotransferase/Aspartate aminotransferase and Alkaline phosphatase (ALP) $<2.5 \times$ ULN in the absence of liver metastases, or $<5 x$ ULN in their presence, (5) Life expectancy $>12$ weeks, (6) written, informed consent.

Exclusion Criteria: (1) Patients with significant metastatic disease volume or rapid disease progression who would be compromised by a delay in commencing chemotherapy (maximum of 3 weeks), (2) other malignant disease, apart from non-melanotic skin cancer or cervical carcinoma in situ, unless the cancer was treated with curative intent over 3 years before enrolment without relapse, (3) medical/psychiatric conditions that compromised the patient's ability to give consent or complete protocol requirements or medical co-morbidities with the potential to be exacerbated by or contra-indicate therapy, (4) prior severe reaction to oxaliplatin, including 
persistent neuropathy (Grade $\geq 1$ ), (5) prior severe reaction to fluoropyrimidines or known dihydropyrimidine dehydrogenase deficiency, (6) if prior adjuvant therapy, relapse within 6 months of a 5 -FU based regimen or within 12 months of an oxaliplatin-based regimen, (7) last dose of radiotherapy received within 4 weeks before treatment start, excluding palliative radiotherapy, (8) treatment with another investigational agent within 28 days, (9) any unresolved toxicity $>\mathrm{NCl}-\mathrm{CTC}$ Grade 2 from previous therapy, (10) co-administration of potent Cytochrome 3A4/5 inducers or inhibitors, (11) active liver disease or a known diagnosis of HIV, and (12) brain metastases or spinal cord compression.

Institutional Ethics Committee approval was obtained.

\section{TREATMENT REGIMEN}

The total treatment period was defined as 26 weeks, comprising of 2 phases: (1) Induction phase: 2 week treatment, from day -14 , whereby patients received imatinib (continuously, p.o.) plus bevacizumab $(5 \mathrm{mg} / \mathrm{kg}$ Intravenous on day -14), to promote normalisation of tumour vasculature followed by; (2) Chemotherapy phase: commencing from day 1, imatinib (continued as above) in combination with a planned twelve cycles of mFOLFOX6bevacizumab. Bevacizumab dose was $5 \mathrm{mg} / \mathrm{kg}$ every 2 weeks. mFOLFOX6 was given as follows: Oxaliplatin $85 \mathrm{mg} / \mathrm{m}^{2} / 2$ hours, Leucovorin $200 \mathrm{mg} / \mathrm{m}^{2} / 2$ hours, 5 -FU $400 \mathrm{mg} / \mathrm{m}^{2} /$ bolus, all on day $1,5-\mathrm{FU}$ continuous infusion 2.4 $\mathrm{g} / \mathrm{m}^{2} / 46$ hours.

Following this 26 week period, patients were followed up as per institutional practice until disease progression or death. Prospectively defined dose 
reductions and omissions based on haematological and non-haematological toxicities were made for relevant agents.

\section{PATIENT EVALUATION:}

Induction phase: Assessments performed on day -14 included physical examination, performance status, toxicity assessment ( $\mathrm{NCl}$ CTC version 3), urine analysis and bloods taken for haematology, biochemistry and tumor markers. On day -7 assessments included toxicity assessment and bloods collected for haematology and biochemistry.

Chemotherapy Phase: (1) Days 1 and 8 of Cycles 1 and 2, patients underwent clinical evaluation, blood collection and urine analysis as above. (2) Cycle 1, Day 14, patients were restaged for tumour response (RECIST criteria). (3) Assessments for Cycles 3 to 12, Day 1 of each subsequent cycle patients underwent clinical evaluation, urine analysis and bloods as above. Response assessment was performed after every 4th cycle of chemotherapy. After completion of 12 chemotherapy cycles, patients were reviewed and offered further treatment as per institutional practice.

\section{IMATINIB DOSE ESCALATION PROTOCOL}

Patients were enrolled into dose levels (DLs) in cohorts of 3 patients. In the Induction phase Imatinib was given continuously from day -14 to day -1 , together with bevacizumab on day -14 , and continued at the same dose during the Chemotherapy phase unless dose reductions were required for toxicity. Three DLs were planned, Dose Level 1 (DL1) 400mg, DL2 600mg and DL3 800mg daily, continuously. 


\section{DOSE ESCALATION PROCEDURE}

Three patients were initially enrolled into each DL: (1) If there were no dose limiting toxicity (DLT) in 3 patients within a cohort a further 3 patients were enrolled into the next DL, (2) If 1 of 3 patients experienced a DLT, then 3 additional patients were accrued (total of 6 patients) to that DL, (3) If $\geq 2$ of 3 patients or $\geq 2$ of 6 patients experienced a DLT, then the next DL down was declared the maximal tolerated dose (MTD). (4) If DLTs were noted in only 1 of 6 patients, then a further 3 patients were enrolled to the next DL. There was no intra-patient dose escalation.

\section{DOSE LIMITING TOXICITY DEFINITION}

DLT was defined within the period of three cycles of imatinib and bevacizumab and two cycles of mFOLFOX6 (i.e. 6 weeks). DLTs were defined as: (1) NCl-CTC Grade 4 neutropenia >7 days, (2) NCI-CTC Grade 4 thrombocytopenia or Grade 3 with bleeding, (3) Febrile neutropenia, (4) Drugrelated $\mathrm{NCl}-\mathrm{CTC}$ Grade 3 or 4 non-haematological toxicity, except alopecia or uncontrolled nausea and vomiting despite standard management, or (5) Delay in the commencement of a subsequent course of chemotherapy of $>2$ weeks.

\section{PHARMACOKINETIC ANALYSIS}

Blood samples were taken for:

(1) Imatinib and CGP074588 (metabolite) analysis: at the following times: Induction phase Day -14 and Chemotherapy phase Cycle 1 Day 1: predose, 
$0.5,1,1.5,2,2.5,4,6,8$ and 24 hrs post dose. Samples were taken for trough levels at Day -7, Cycle 1 Day 7 and Cycle 2 Day 1.

(2) Oxaliplatin (Total and Ultrafiltrate) analysis: Day 1 Cycle 1: predose, 0.5, 1, $1.92,2.5,3,4,6,8$ and 24 hrs post start infusion.

(3) 5FU analysis: Cycle 1 Day 1; Pre dose, 3, 6, 24, 46 hrs post-start of infusion and 15, 30, 90mins post end of 5FU infusion.

\section{Drug analysis:}

(1) Imatinib and CGP074588 plasma levels: determined using HPLC with UV detection at $267 \mathrm{~nm}$. Plasma proteins were precipitated using methanol and the supernatant injected on to a reverse-phase HPLC column (Kromasil-C8 $5 \mu \mathrm{m}, 250 \times 4.6 \mathrm{~mm})$. Analysis was performed at the Royal Adelaide Hospital, Adelaide, Australia.

(2) 5FU plasma level determination: 5FU was extracted from plasma by liquidliquid extraction (LLE) using Chem-Elute Extube cartridges,[3] subsequent elution was achieved with ethyl acetate:methanol, 95:5. The resulting extract was evaporated under air at $45^{\circ} \mathrm{C}$ and the residue reconstituted in mobile phase. This was then injected onto a Spherisorb $5 \mu \mathrm{m}$ ODS2, $4.6 \times 250 \mathrm{~mm}$, C18 HPLC column (Waters) fitted with a Nova-Pak-C18 Guard-Pak precolumn (Waters). Separation was achieved on a Waters 2690 HPLC system using isocratic conditions. Detection of 5FU and thymine (internal standard) was at $267 \mathrm{~nm}$. This analysis and that of oxaliplatin was performed at the Peter MacCallum Cancer Centre.

(3) Oxaliplatin and Ultrafiltrate plasma level determination: Total and unbound platinum was measured in patient plasma and plasma ultrafiltrate 
respectively, at $2700^{\circ} \mathrm{C}$, using graphite furnace atomic absorption spectrometry (Varian SpectrAA 600Z) at $265.9 \mathrm{~nm}$. Plasma ultrafiltrates were prepared by centrifugation through Centrisart-I units (cut off 20,000 Da, Sartorius). Platinum levels in plasma and plasma ultrafiltrates were quantified using platinum chloride standards prepared in matrix matched diluent.

\section{Pharmacokinetic Parameter Derivation:}

All plasma concentration-time data were analysed using non-compartmental methods with WinNonLin Professional version 5.2. Parameters derived for the respective drugs included: (1) Imatinib and metabolite: $C_{s s}, A U C_{0-24 h r s ~}$ day -14 and Cycle 1 day $1, \mathrm{AUC}_{0-336 \mathrm{hrs}}$ (pre-chemo, day -14 to Cycle 1 day 1 ), $\mathrm{AUC}_{336-}$ 672hrs (post chemo, Cycle 1 day 1 to day 14), CL/F, CL $L_{s s}, t_{1 / 2 .}$ (2) Oxaliplatin: $\mathrm{C}_{\max }, \mathrm{t}_{1 / 2}, \mathrm{AUC}_{0-24 h r s}, \mathrm{AUC}_{0-\infty}, \mathrm{CL}$, (3) $5 \mathrm{FU}: \mathrm{CL}, \mathrm{C}_{\mathrm{ss}}$ and $\mathrm{AUC}_{0-24 h r s}$

PK parameters were summarised by the arithmetic mean, standard deviation (SD), coefficient of variation ( $\mathrm{CV}=100 \%[\mathrm{SD} / \mathrm{Mean}]$ ), and number of observations $(M)$.

\section{STATISTICAL ANALYSES}

Performed using SAS software. Demographic, clinical and laboratory baseline data were presented using descriptive statistics. Descriptive statistics were used to describe the treatment received, the number of patients in each DL, details of the DLTs, the best response to treatment,[41] as well the number of patients experiencing AEs. The dose intensity and treatment cycles started for all patients were also summarised. Laboratory data were presented using descriptive statistics. Descriptive statistics included the number of 
observations $(M)$, mean, SD, median, minimum (Min) and maximum (Max) for quantitative variables and counts and percentages for categorical variables. 


\section{RESULTS}

\section{PATIENTS:}

Overall 10 patients were accrued, 3 patients in DL1 (400mg imatinib) and 7 in DL2 (600mg). The patient demographics are summarised in Table 1.

\section{DOSE ADMINISTRATION AND ESCLATION:}

Dose level 1 comprised of 3 patients who received imatinib 400mg. No patient in DL1 had experienced a DLT, hence DL2 (imatinib 600mg) was opened. In total, 7 patients were accrued to DL2, 1 patient had progressive disease during the Induction phase and was therefore replaced. Overall 3 of these 7 patients experienced a DLT (febrile neutropenia $N=2$, and oral cavity infection with Grade 4 neutropenia $N=1$ ). As prospectively defined in the protocol, the patients who suffered these DLTs had all treatment interrupted with subsequent dose modification on recovery. Thus DL1 was declared the Maximal Tolerated Dose (MTD).

The number of cycles delivered for each DL is shown in Table 2. All patients in DL1 completed the 12 planned cycles of imatinib + mFOLFOX6bevacizumab. In DL2, 1 patient completed the planned 12 cycles. The reasons for non-completion of the planned therapy in DL2 included: repeated episodes of Grade 3 neutropenia, febrile neutropenia, fatigue, ( $N=1$, respectively), progressive disease $(N=2)$ and other reasons $(N=1)$. The dose intensity of imatinib + mFOLFOX6-bevacizumab during the delivered cycles was in excess of $80 \%$ for both DLs. (Table 2 )

The most common AEs were haematological, predominantly neutropenia, as detailed in Table 3: over $60 \%$ of patients in both DLs 
experiencing grade 3 or 4 neutropenia. In DL2, 4 of the 6 evaluable patients had grade 3 and 1 had grade 4 neutropenia. Non-haematological AEs are summarised in Table 4. These were as expected for the mFOLFOXbevacizumab regimen. Notably though, 2 of 6 patients in DL2 suffered febrile neutropenia.

Imatinib was interrupted for the following reasons: In DL1 $(N=3)$ : grade 3 neutropenia in 2 patients (on 4 occasions), Grade 3 fatigue in 1 patient (on 2 occasions), non-neutropenic infection (dental abscess) in cycle 1 in 1 patient. In DL2 (N=7): Grade 3 or 4 neutropenia in 4 pts on 4 occasions and febrile neutropenia in 2 patients; 1 patient in cycle 1 and the other in cycles 1 and 5 .

In DL1 and DL2, mFOLFOX6 was interrupted when imatinib was withheld. In addition one patient in DL1 had developed Grade 3 sensory neuropathy in cycle 9. In DL2 one patient had interruption of bevacizumab due to grade 2 hypertension in cycle 11.

\section{PHARMACOKINETICS}

The pharmacokinetics of oxaliplatin (Total and Ultrafiltrate), imatinib (parent and metabolite CGP074588) and 5FU in DL1 and DL2 are summarised in Table 5. There was no statistically significant difference between the pharmacokinetics of oxaliplatin and 5FU between the dose levels.

With regard to imatinib in DL1 there was no difference between the PK parameters from $0-24 \mathrm{hrs}$ on Day -14 (prechemotherapy) relative to Day 1 (post chemotherapy). However this was not the case for patients in DL2, where there was a statistically reduced $\mathrm{CL}$ of both parent $(6.58 \mathrm{~L} / \mathrm{hr}$ versus 
4.37L/hr, $P<0.05)$ and metabolite $(39.1 \mathrm{~L} / \mathrm{hr}$ versus $14.8 \mathrm{~L} / \mathrm{hr}, P<0.05)$. This was also manifest by a more prolonged $t_{1 / 2}$ post chemotherapy that was only significant for the parent drug: 13.5hrs versus $19.1 \mathrm{hrs}, P<0.05$.

Steady state PK of imatinib and its metabolite pre- and postchemotherapy was assessed by the comparison between $\mathrm{AUC}_{0-336 \mathrm{hrs}}$ (Prechemo: Day -14 to Cycle 1 day 1), versus $\mathrm{AUC}_{336-672 \mathrm{hrs}}$ (Post chemo, Cycle 1: day 1 to 14). There was a trend to higher AUC especially for DL2 post chemotherapy however this did not reach statistical significance. Overall the exposure parameters showed a non-linear increase with respect to imatinib dose for parent and metabolite.

\section{EFFICACY:}

The overall best response in the three patients in DL1 was one PR and two SD. In DL2, 5 patents had SD (71.4\%) and two patients had PD (28.6\%). For the entire patient population the best response were $1 \mathrm{PR}(10 \%), 7 \mathrm{SD}$ (70\%) and 2 PD. 


\section{DISCUSSION}

The study reported here was the first attempt to combine continuous dosing of imatinib with full dose mFOLFOX6-bevacizumab in patients with advanced CRC. It was assumed that the imatinib steady state levels $\left(C_{s s}\right)$ achieved by the two dose levels evaluated would be associated with in-vitro inhibition of PDGFR: i.e. in excess of its $I_{50}$.[6] In support of this, doses of imatinib of $400 \mathrm{mg}$ or greater were sufficient to induce responses in dermatofibrosarcoma protuberans, a tumour driven by PDGFB.[26, 36]

The aims of this trial were thus to (i) define the MTD of dose escalated imatinib in combination with mFOLFOX6-bevacizumab, (ii) define the toxicity and potential PK interactions of the combination. The study demonstrated sufficient safety information to indicate the inability to dose escalate continuous imatinib: the achieved MTD was well below that of continuous single agent imatinib.

The pharmacokinetic parameters for imatinib were comparable to reported single agent studies.[12, 19, 22, 31] The imatinib $C_{s s}$ observed for DL1 and DL2 was in excess of $0.56 \mu \mathrm{M}$ : sufficient to substantially inhibit PDGFR signalling assuming that plasma concentration approximated to intratumour concentrations $\left(\mathrm{IC}_{50}=0.1-1.0 \mu \mathrm{M}\right)$.[6] Similarly, PK parameters for oxaliplatin and 5FU were as for other similar FOLFOX regimens.[7, 27-28] Thus imatinib appears to have had no impact on the PK of oxaliplatin and 5FU. However the study did not examine the administration of mFOLFOX6bevacizumab pre- and post- the administration of imatinib to determine this directly. 
Interestingly in DL2 there was an increased AUC (and reduced $\mathrm{CL}$ ) for both imatinib and metabolite from day-14 (pre-chemotherapy) relative to day 1 (post-chemotherapy), $(P<0.05)$, respectively (Table 5$)$. There are 2 possible explanations for this observation. The first, this observation may be the result of steady state not being achieved during the sampling time whereby a $1.5-$ to three-fold drug accumulation occurs after once-daily dosing from the beginning of dosing till the achievement of steady state [21, 32] The other explanation may be actual changes with $\mathrm{CL}$ over time. The reported $\mathrm{CL}$ changes with time have been inconsistent: chronic exposure studies have demonstrated, albeit non-significant trends to increased imatinib CL over a 6 or 12 months chronic exposure.[11, 19], but a smaller study with sampling over 60 days observed a decrease in imatinib $C L$ with time.[9] It must be noted that the study reported here was limited by small patient numbers with sampling limited to 28 days.

The mechanism of a reduced CL of imatinib between pre- and postchemotherapy at the higher dose examined in DL2 is unclear. Oxaliplatin and 5FU are not hepatically cleared. Imatinib and its metabolite are metabolised predominantly by hepatic CYP3A and excreted by the biliary-faecal route.[23] A phase I study of a bolus/infusional 5FU regimen with imatinib, observed no alterations in the imatinib PK.[1] However, there is no data describing the impact of oxaliplatin or bevacizumab on imatinib PK. Similarly, for oxaliplatin or $5 \mathrm{FU}$ on the biliary transporters responsible for imatinib excretion. It is also unclear if chemotherapy-induced mucosal injury within the gastrointestinal tract may have an impact on the activity of enterocyte CYP3A4 and ABCB1, hence altering the first pass metabolism of imatinib. Similarly, patients in DL2 
did not have serum liver biochemistry elevations consistent with disease progression or cytotoxic-induced hepatic injury to account for a change in imatinib handling.

In this study, the most common adverse events were haematologcial, predominantly neutropenia (Table 3 ). The observed toxicity is greater than with mFOLFOX6-bevacizumab alone based on the reported phase III trials in advanced CRC patients.[8, 13, 15] In these studies the observed rates of combined Grade 3-4 neutropenia range from 24-49\%,[8, 13, 15] and Grade 4 alone in $19 \%$.[8] The reason for the excess toxicity may reflect the small sample size in each cohort, but patients were not heavily pretreated. The increase in toxicity may reflect the altered imatinib PK described above or a pharmacodynamic interaction. PDGF and VEGF also both have roles in hematopoieisis.[2] Single agent imatinib in gastrointestinal stromal tumor patients was associated with Grade 3-4 neutropenia in approximately 7\% and $3 \%$ at the $400 \mathrm{mg}$ and $600 \mathrm{mg}$ dose levels, respectively.[10]. There are other studies with imatinib and with crenolanib (CP-868,596 a selective PDGFR inhibitor) combined with chemotherapy that had resulted in unexpected increased toxicity.[16, 40, 43, 45]

A phase I/II trial has reported the safety and efficacy of imatinib with oxaliplatin-capecitabine-bevacizumab in 49 patients with untreated CRC. The MTD was capecitabine $850 \mathrm{mg} / \mathrm{m}^{2}$ bid days $1-14$, oxaliplatin $100 \mathrm{mg} / \mathrm{m}^{2}$ and bevacizumab $7.5 \mathrm{mg} / \mathrm{kg}$ day 1 of a 21 day cycle with imatinib at $300 \mathrm{mg}$ daily.[43] The MTD represents a $15 \%$ and $23 \%$ dose reduction for the cytotoxics, respectively, with the $400 \mathrm{mg}$ continuous dosing of imatinib not deliverable. The most common Grade 3-4 toxicities were non-haematologcial 
The overall response rate was $47 \%$ and median PFS of 11.1 months $(95 \% \mathrm{Cl}$ : 9.5-16).[43]

A phase II trial in patients with metastatic breast cancer reported on the combination of imatinib with docetaxel as first-line treatment.[45] Initially, patients received imatinib $600 \mathrm{mg}$ daily and docetaxel $30 \mathrm{mg} / \mathrm{m}^{2}$ weekly for three weeks on a 28-day cycle. The imatinib dose was lowered to $400 \mathrm{mg}$ daily due to toxicity. The regimen overall was poorly tolerated, primarily because of gastrointestinal toxicity.[45] A two arm phase lb trial treated 48 patients with the potent oral PDGFR inhibitor CP-868,596 (60-100mg bid) combined with docetaxel $\left(75-100 \mathrm{mg} / \mathrm{m}^{2}\right)$, or with the combination of $\mathrm{CP}$ 868,596 (60mg bid), docetaxel $\left(75 \mathrm{mg} / \mathrm{m}^{2}\right)$ and the VEGFR inhibitor axitinib (5 mg bid). The triplet combination could not be dose escalated due to the increased incidence of mucositis-like AEs with concurrent neutropenia relative to that expected for docetaxel alone.[29]

The overall response rate for the patients evaluated in this current study was less than expected given that these patients were being treated in the first-line setting. This was despite the achieved $C_{s s}$ levels of imatinib known to be associated with PDGFR inhibition and full dose of mFOLFOX6bevacizumab. The trial's primary endpoint was not radiological response rate and as above the cohort was small in size. For the entire patient population the response rates were: $1 \mathrm{PR}(10 \%), 7 \mathrm{SD}(70 \%)$. In the randomized phase III trials of patients with untreated metastatic CRC receiving FOLFOX + bevacizumab, the reported response rates ranged from 38 to $52 \%$. [8, 15, 39] It is conceivable that better tolerability may have been achieved at a DL-1 level of $300 \mathrm{mg}$ daily of imatinib, whilst retaining possibly effective inhibition of 
PDGFR. However, data from this study as well as the other combination approaches reviewed above did not lend encouragement to proceed in this direction.

In conclusion the study reported here was the first attempt to combine escalating doses of continuous imatinib with full dose mFOLFOX6bevacizumab in patients with previously untreated advanced CRC. The imatinib continuous dosing had achieved $\mathrm{C}_{\mathrm{ss}}$ levels likely to be sufficient to inhibit PDGRFR.[6] The imatinib dose of $400 \mathrm{mg}$ was the MTD in combination with full dose mFOLFOX6-bevacizumab. The study provided sufficient safety information to indicate the inability to dose escalate imatinib beyond $400 \mathrm{mg}$. 
Table 1: Patient demographics. 


\begin{tabular}{|c|c|c|}
\hline \multicolumn{2}{|l|}{ Parameter } & \multirow{2}{*}{$\begin{array}{l}\text { No. }(\%) \\
(\mathrm{N}=10) \\
61\end{array}$} \\
\hline Age & Mean & \\
\hline & Range & $45.6-74$ \\
\hline \multirow[t]{2}{*}{ Gender } & Male & $7(70.0 \%)$ \\
\hline & Female & $3(30.0 \%)$ \\
\hline \multirow[t]{2}{*}{ ECOG Performance Status } & 0 & $8(80.0 \%)$ \\
\hline & 1 & $2(20.0 \%)$ \\
\hline \multirow[t]{2}{*}{ Disease status } & Locally advanced & $0(0.0 \%)$ \\
\hline & Metastatic & $10(100.0 \%)$ \\
\hline \multirow[t]{5}{*}{ Metastatic sites } & Liver & $7(70.0 \%)$ \\
\hline & Lung & $2(20.0 \%)$ \\
\hline & Lymph nodes & $8(80.0 \%)$ \\
\hline & Pelvic mass & $1(10.0 \%)$ \\
\hline & Peritoneum & $1(10.0 \%)$ \\
\hline \multirow[t]{2}{*}{ Prior chemotherapy } & Yes & $1^{\mathrm{a}}(10.0 \%)$ \\
\hline & No & $9(90.0 \%)$ \\
\hline \multirow[t]{2}{*}{ Prior radiotherapy } & Yes & $0(0.0 \%)$ \\
\hline & No & $10(100.0 \%)$ \\
\hline \multirow[t]{2}{*}{ Site of primary } & Colon & $8(80 \%)$ \\
\hline & Rectum & $2(20 \%)$ \\
\hline
\end{tabular}

a Prior adjuvant chemotherapy 
Table 2. Delivery of Imatinib + mFOLFOX6-bevacizumab. 


\begin{tabular}{c|c|c}
\hline Parameter & $\begin{array}{c}\text { DL1: Imatinib 400 mg/day } \\
+ \text { mFOLFOX6-bevacizumab. } \\
(n=3)\end{array}$ & $\begin{array}{c}\text { DL2: Imatinib 600mg/day } \\
+ \text { mFOLFOX6-bevacizumab } \\
(\mathbf{n}=7)\end{array}$ \\
\hline
\end{tabular}

\begin{tabular}{c|c|c}
\multicolumn{3}{c}{ Patients per number of cycles delivered } \\
\hline $\begin{array}{c}\text { Total no. of cycles of } \\
\text { mFOLFOX6- } \\
\text { bevacizumab. }\end{array}$ & Number of patients & Number of patients \\
\hline 1 & 3 & $7^{\text {a }}$ \\
4 & 3 & 6 \\
8 & 3 & 3 \\
12 & 2 \\
\hline
\end{tabular}

\begin{tabular}{l|c|c|c|c}
\hline \multicolumn{5}{c}{ Dose Intensity ${ }^{\mathrm{b}}$ for each Drug } \\
\hline Drug & Mean (SD) & Range & Mean (SD) & Range \\
\hline Imatinib & $0.810(0.118)$ & $0.713-0.942$ & $0.798(0.245)$ & $0.348-1.000$ \\
\hline Oxaliplatin & $0.860(0.037)$ & $0.833-0.902$ & $0.874(0.108)$ & $0.737-1.000$ \\
\hline 5FU Infusion & $0.891(0.039)$ & $0.854-0.931$ & $0.902(0.088)$ & $0.795-1.000$ \\
\hline Bevacizumab & $0.922(0.088)$ & $0.826-0.998$ & $1.00(0.028)$ & $0.963-1.0$ \\
\hline
\end{tabular}

${ }^{a^{*}}$ One patient had progressed within the Induction phase and hence was replaced

${ }^{\mathrm{b}}$ Dose Intensity = Total dose delivered divided by number of weeks of actual treatment 
Table 3 : Haematological toxicity (NCl CTC version 3), by dose level (DL) over the study period. 


\begin{tabular}{llcccc}
\hline \multirow{2}{*}{$\begin{array}{l}\text { Imatinib } \\
\text { Dose level }\end{array}$} & Toxicity & Grade 1 & Grade 2 & Grade 3 & Grade 4 \\
\cline { 3 - 6 } & & & & & \\
\hline $400 \mathrm{mg}$ & Haemoglobin & 1 & 0 & 0 & 0 \\
$(\mathrm{n}=3)$ & Platelets & 2 & 0 & 0 & 0 \\
& WCC & 0 & 0 & 0 & 0 \\
& Neutrophils & 0 & 0 & 2 & 1 \\
\hline $600 \mathrm{mg}$ & Haemoglobin & $1(14 \%)$ & $0(0.0 \%)$ & $0(0.0 \%)$ & $0(0.0 \%)$ \\
$(\mathrm{n}=7)$ & Platelets & $0(0.0 \%)$ & $0(0.0 \%)$ & $0(0.0 \%)$ & $0(0.0 \%)$ \\
& WCC & $0(0.0 \%)$ & $0(0.0 \%)$ & $0(0.0 \%)$ & $0(0.0 \%)$ \\
& Neutrophils & $0(0.0 \%)$ & $0(0.0 \%)$ & $4(57 \%)$ & $1(14 \%)$ \\
\hline
\end{tabular}


Table 4: Non-haematological Adverse events ( $\mathrm{NCI}$ CTC version 3), by dose level considered related to study drugs by dose level (DL) over the study period. 


\begin{tabular}{|c|c|c|c|}
\hline Dose level & Adverse Event & Worst grade & No. Patients \\
\hline DL1 (400 mg) & Diarrhea & 1 & 2 \\
\hline \multirow[t]{12}{*}{$(n=3)$} & Nausea & 1 & 1 \\
\hline & & 2 & 2 \\
\hline & Fatigue & 1 & 1 \\
\hline & & 3 & 1 \\
\hline & Hemorrhage, Gl & 1 & 1 \\
\hline & $\begin{array}{l}\text { Hemorrhage, pulmonary/upper } \\
\text { respiratory }\end{array}$ & 1 & 1 \\
\hline & Hypertension & 1 & 1 \\
\hline & & 3 & 1 \\
\hline & Infection - Non-neutropenic & 1 & 1 \\
\hline & Mucositis/stomatitis & 1 & 1 \\
\hline & Watery eye (epiphora, tearing) & 1 & 1 \\
\hline & Neuropathy: sensory & 1 & 3 \\
\hline \multirow[t]{13}{*}{$\begin{array}{l}\text { DL } 2(600 \mathbf{m g}) \\
(\mathrm{n}=7)\end{array}$} & Anorexia & $\begin{array}{l}1 \\
2\end{array}$ & $\begin{array}{l}2(29 \%) \\
2(29 \%)\end{array}$ \\
\hline & Diarrhea & 1 & $3(43 \%)$ \\
\hline & Esophagitis & 2 & $1(14 \%)$ \\
\hline & Nausea & $\begin{array}{l}1 \\
2 \\
4\end{array}$ & $\begin{array}{l}2(29 \%) \\
2(29 \%) \\
1(14 \%)\end{array}$ \\
\hline & Vomiting & $\begin{array}{l}1 \\
2 \\
4\end{array}$ & $\begin{array}{l}3(43 \%) \\
1(14 \%) \\
1(14 \%)\end{array}$ \\
\hline & Fatigue & $\begin{array}{l}1 \\
2 \\
3\end{array}$ & $\begin{array}{l}2(29 \%) \\
1(14 \%) \\
1(14 \%)\end{array}$ \\
\hline & Febrile neutropenia & 4 & $2(29 \%)$ \\
\hline & Hemorrage/Bleeding & 1 & $1(14 \%)$ \\
\hline & Hypertension & 2 & $1(14 \%)$ \\
\hline & Mucositis/stomatitis & $\begin{array}{l}1 \\
2\end{array}$ & $\begin{array}{l}1(14 \%) \\
1(14 \%)\end{array}$ \\
\hline & Neuropathy: sensory & $\begin{array}{l}1 \\
2\end{array}$ & $\begin{array}{l}3(43 \%) \\
1(14 \%)\end{array}$ \\
\hline & GGT & 3 & $1(14 \%)$ \\
\hline & Alkaline phosphatase & 2 & $1(14 \%)$ \\
\hline
\end{tabular}


Table 5: Summary of oxaliplatin (Total and Ultrafiltrate), imatinib (parent and metabolite CGP074588) and 5FU pharmacokinetics in Dose Levels 1 and 2. 


\begin{tabular}{|c|c|c|c|c|}
\hline Parameter $^{\dagger}$ & $\begin{array}{r}\text { Dose L } \\
\text { Imatinib } \\
\text { Mean } \\
\mathbf{N}\end{array}$ & $\begin{array}{l}1 \\
\text { Omg) } \\
\% \text { ) }\end{array}$ & $\begin{array}{r}\text { Dose } \\
\text { Imatini } \\
\text { Mean } \\
\mathbf{N}\end{array}$ & $\begin{array}{l}\text { evel } 2 \\
600 \mathrm{mg} \\
\mathrm{CV} \%) \\
5\end{array}$ \\
\hline Oxaliplatin & & & & \\
\hline & Total Platinum & Ultrafiltrate & Total Platinum & Ultrafiltrate \\
\hline 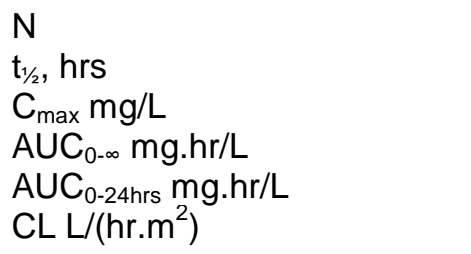 & $\begin{array}{c}3 \\
33.9(11.65) \\
3.8(6.38) \\
131.61(13.5) \\
51.0(6.6) \\
0.65(12.7)\end{array}$ & $\begin{array}{c}3 \\
17.35(12.3) \\
0.38(24.2) \\
9.04(24.6) \\
5.4(15.8) \\
9.8(25.5)\end{array}$ & $\begin{array}{c}7 \\
34.8(8.1) \\
4.29(13.9) \\
156.15(19.9) \\
58.7(16.2) \\
0.56(19.9)\end{array}$ & $\begin{array}{c}6 \\
19.3(29.7) \\
0.84(47.2) \\
11.7(26.8) \\
6.9(25.7) \\
7.7(26.3)\end{array}$ \\
\hline Imatinib: Day -14 and Day 1 & $24 \mathrm{hr}$ PK & & & \\
\hline & Par & & & \\
\hline & $\begin{array}{c}\text { Day -14, } \\
\text { 0-24hr PK }\end{array}$ & $\begin{array}{c}\text { Day 1, } \\
0-24 \mathrm{hr} \text { PK }\end{array}$ & $\begin{array}{c}\text { Day -14, } \\
\text { 0-24hr PK }\end{array}$ & $\begin{array}{c}\text { Day 1, } \\
\text { 0-24hr PK }\end{array}$ \\
\hline $\begin{array}{l}\mathrm{N} \\
\mathrm{t}_{1 / 2}, \mathrm{hrs} \\
\mathrm{C}_{\max } \mathrm{ng} / \mathrm{ml} \\
\mathrm{AUCC}_{0-24 h r s} \mathrm{ng} \cdot \mathrm{hr} / \mathrm{ml} \\
\mathrm{CL} \mathrm{F} \mathrm{L/hr}\end{array}$ & $\begin{array}{c}3 \\
12.46(5.9) \\
2183.3(22.7) \\
27210.8(38.3) \\
11.7(38.5)\end{array}$ & $\begin{array}{c}3 \\
13.2(42.4) \\
2770(18.3) \\
34606(17.3) \\
8.5(17.8)\end{array}$ & $\begin{array}{c}7 \\
13.5(14.6) \\
5805.7(50.1) \\
78937.1(49.1) \\
6.58(50.6)\end{array}$ & $\begin{array}{c}5 \\
19.1(16.9)^{\mathrm{a}} \\
6184(44.7)^{\mathrm{a}} \\
97915.5(48.4)^{\mathrm{a}} \\
4.37(55.5)^{\mathrm{a}}\end{array}$ \\
\hline & CGP0 & & CGP & 4588 \\
\hline & $\begin{array}{l}\text { Day -14, } \\
\text { 0-24hr PK }\end{array}$ & $\begin{array}{c}\text { Day 1, } \\
\text { 0-24hr PK }\end{array}$ & $\begin{array}{l}\text { Day -14, } \\
\text { 0-24hr PK }\end{array}$ & $\begin{array}{c}\text { Day 1, } \\
\text { 0-24hr PK }\end{array}$ \\
\hline $\begin{array}{l}\mathrm{N} \\
\mathrm{t}_{1 / 2}, \mathrm{hrs}\end{array}$ & $\begin{array}{c}3 \\
21.6(0)((\mathrm{N}=1)\end{array}$ & $\begin{array}{c}3 \\
57.2(18.1) \\
(\mathrm{N}=2)\end{array}$ & $\begin{array}{c}6 \\
24.5(46.2)\end{array}$ & $\begin{array}{c}5 \\
40.1(41.5)\end{array}$ \\
\hline $\begin{array}{l}\mathrm{C}_{\max } \mathrm{ng} / \mathrm{ml} \\
\mathrm{AUC}_{0-24 \mathrm{hrs}} \mathrm{ng} \cdot \mathrm{hr} / \mathrm{ml}\end{array}$ & $\begin{array}{c}223.3(22.1) \\
4560(0)(\mathrm{N}=1)\end{array}$ & $\begin{array}{c}426.7(25.1) \\
6861.2(47.7)\end{array}$ & $\begin{array}{c}698.3(42.6) \\
10201.7(48.0)\end{array}$ & $\begin{array}{c}1088(55)^{\mathrm{a}} \\
20557(56.7)\end{array}$ \\
\hline CL F L/hr & $44.9(0)(\mathrm{N}=1)$ & $\begin{array}{c}15.8(34.7) \\
(\mathrm{N}=2)\end{array}$ & $39.1(72.2)$ & $14.8(68.3)^{\mathrm{a}}$ \\
\hline Imatinib Steady State PK, De & 14 to Day 14 & & & \\
\hline & Parent & CGP074588 & Parent & CGP074588 \\
\hline $\begin{array}{l}\mathrm{N} \\
\mathrm{C}_{\mathrm{sS}} \mathrm{ng} / \mathrm{ml} \\
\text { AUC }_{0-336 \mathrm{hrs}} \\
\text { (Pre-chemo: Day }-14 \text { to }\end{array}$ & $\begin{array}{c}3 \\
882.6(35.9) \\
286600(42.2)\end{array}$ & $\begin{array}{l}3 \\
218.9(43.1) \\
60160(51.7)\end{array}$ & $\begin{array}{c}7 \\
2150(47.3) \\
667062.9(41.3)\end{array}$ & $\begin{array}{c}7 \\
501.8(59.8) \\
150934.3(58.2)\end{array}$ \\
\hline $\begin{array}{l}\text { AUC }_{336-672 h r s} \\
\text { (Post chemo, Cycle 1: day 1- } \\
\text { 14), ng.hr/ml }\end{array}$ & $306520(31.1)$ & $86960(37.6)$ & $\begin{array}{c}813960(64.4) \\
\quad(N=4)\end{array}$ & $\begin{array}{l}201930(70.9) \\
\quad(\mathrm{N}=4)\end{array}$ \\
\hline $\mathrm{CL}_{s s} \mathrm{~F} \mathrm{L/hr}$ & $64.5(43.8)$ & $1181.2(90)$ & $34.9(48.5)$ & $501.8(160.1)$ \\
\hline 5FU Steady State PK & & & & \\
\hline $\begin{array}{l}\mathrm{N} \\
\mathrm{C}_{\text {ss }} \mathrm{ng} / \mathrm{ml} \\
\mathrm{CL}_{\text {ss }} \mathrm{L} /\left(\mathrm{hr} \cdot \mathrm{m}^{2}\right) \\
\mathrm{AUC}_{0-24 \mathrm{hrs}} \mathrm{hr} \cdot \mathrm{ng} / \mathrm{ml} \\
\end{array}$ & $\begin{array}{r}429.3 \\
130.8 \\
9613.6 \\
\end{array}$ & & $\begin{array}{l}310 . \\
191 . \\
6927\end{array}$ & $\begin{array}{l}34.0) \\
41.0) \\
(23.0) \\
\end{array}$ \\
\hline
\end{tabular}

a. $\mathrm{P}<0.05$ Wilcoxon rank-sum test Day 1 relative to Day $-140-24 \mathrm{hr}$ PK parameters 


\section{ACKNOWLEDGEMENTS}

I would like to thank the analytical staff of the Translational Research Laboratory, Peter MacCallum Cancer Centre for the oxaliplatin and 5FU analysis. I would also thank the analytical staff of the Royal Adelaide Hospital for the imatinib analysis.

\section{FUNDING}

This work was supported by funding from Novartis Australia.

\section{CONFLICTS OF INTEREST}

M Michael: No conflict of interest

J. Zalcberg: Travel and Research Funding and Honorarium

K Lynch: Previous employee of Novartis Australia

M Copeman: Employee of Novartis Australia

G McArthur: Research funding from Novartis.

$M$ Jefford No conflict of interest

M Gouillou: No conflict of interest

P Gibbs: No conflict of interest

L Lipton: No conflict of interest

NC Tebbutt: No conflict of interest 


\section{REFERENCES}

[1] Al-Batran SE, Atmaca A, Schleyer E, Pauligk C, Hosius C, Ehninger G, Jager E (2007) Imatinib mesylate for targeting the platelet-derived growth factor beta receptor in combination with fluorouracil and leucovorin in patients with refractory pancreatic, bile duct, colorectal, or gastric cancer--a doseescalation Phase I trial. Cancer 109: 1897-904

[2] Andrae J, Gallini R, Betsholtz C (2008) Role of platelet-derived growth factors in physiology and medicine. Genes Dev 22: 1276-312

[3] Barberi-Heyob M, Merlin JL, Weber B (1992) Analysis of 5-fluorouracil in plasma and urine by high-performance liquid chromatography. $J$ Chromatogr 581: 281-6

[4] Bergers G, Song S, Meyer-Morse N, Bergsland E, Hanahan D (2003) Benefits of targeting both pericytes and endothelial cells in the tumor vasculature with kinase inhibitors. J Clin Invest 111: 1287-95

[5] Board R, Jayson GC (2005) Platelet-derived growth factor receptor (PDGFR): a target for anticancer therapeutics. Drug Resist Updat 8: 75-83

[6] Buchdunger E, Zimmermann J, Mett $\mathrm{H}$, Meyer T, Muller M, Druker BJ, Lydon NB (1996) Inhibition of the Abl protein-tyrosine kinase in vitro and in vivo by a 2-phenylaminopyrimidine derivative. Cancer Res 56: 100-4

[7] Burz C, Berindan-Neagoe I, Balacescu O, Todor N, Pelau D, Floares C, Kacso G, Tanaselia C, Ursu M, Vlase L, Leucuta SE, Cristea V, Irimie A (2010) Oxaliplatin in patients with metastatic colorectal cancer: efficacy and pharmacokinetics parameters. J BUON 15: 263-9 
[8] Cassidy J, Clarke S, Diaz-Rubio E, Scheithauer W, Figer A, Wong R, Koski S, Lichinitser M, Yang TS, Rivera F, Couture F, Sirzen F, Saltz L (2008) Randomized phase III study of capecitabine plus oxaliplatin compared with fluorouracil/folinic acid plus oxaliplatin as first-line therapy for metastatic colorectal cancer. J Clin Oncol 26: 2006-12

[9] Delbaldo C, Chatelut E, Re M, Deroussent A, Seronie-Vivien S, Jambu A, Berthaud P, Le Cesne A, Blay JY, Vassal G (2006) Pharmacokineticpharmacodynamic relationships of imatinib and its main metabolite in patients with advanced gastrointestinal stromal tumors. Clin Cancer Res 12: 6073-8 [10] Demetri GD, von Mehren M, Blanke CD, Van den Abbeele AD, Eisenberg B, Roberts PJ, Heinrich MC, Tuveson DA, Singer S, Janicek M, Fletcher JA, Silverman SG, Silberman SL, Capdeville R, Kiese B, Peng B, Dimitrijevic S, Druker BJ, Corless C, Fletcher CD, Joensuu H (2002) Efficacy and safety of imatinib mesylate in advanced gastrointestinal stromal tumors. $\mathrm{N}$ Engl J Med 347: 472-80

[11] Eechoute K, Fransson MN, Reyners AK, de Jong FA, Sparreboom A, van der Graaf WT, Friberg LE, Schiavon G, Wiemer EA, Verweij J, Loos WJ, Mathijssen $\mathrm{RH}$, De Giorgi $U$ (2012) A long-term prospective population pharmacokinetic study on imatinib plasma concentrations in GIST patients. Clin Cancer Res

[12] Frye RF, Fitzgerald SM, Lagattuta TF, Hruska MW, Egorin MJ (2004) Effect of St John's wort on imatinib mesylate pharmacokinetics. Clin Pharmacol Ther 76: 323-9

[13] Hecht JR, Mitchell E, Chidiac T, Scroggin C, Hagenstad C, Spigel D, Marshall J, Cohn A, McCollum D, Stella P, Deeter R, Shahin S, Amado RG 
(2009) A randomized phase IIIB trial of chemotherapy, bevacizumab, and panitumumab compared with chemotherapy and bevacizumab alone for metastatic colorectal cancer. J Clin Oncol 27: 672-80

[14] Hellstrom M, Kalen M, Lindahl P, Abramsson A, Betsholtz C (1999) Role of PDGF-B and PDGFR-beta in recruitment of vascular smooth muscle cells and pericytes during embryonic blood vessel formation in the mouse. Development 126: 3047-55

[15] Hochster HS, Hart LL, Ramanathan RK, Childs BH, Hainsworth JD, Cohn AL, Wong L, Fehrenbacher L, Abubakr Y, Saif MW, Schwartzberg L, Hedrick E (2008) Safety and efficacy of oxaliplatin and fluoropyrimidine regimens with or without bevacizumab as first-line treatment of metastatic colorectal cancer: results of the TREE Study. J Clin Oncol 26: 3523-9

[16] Huang $\mathrm{CH}$, Williamson SK, Van Veldhuizen PJ, Hsueh CT, Allen A, Tawfik O, Wick J, Smith H, Uypeckcuat AM, Mayo M, Kelly K (2011) Potential role of platelet-derived growth factor receptor inhibition using imatinib in combination with docetaxel in the treatment of recurrent non-small cell lung cancer. J Thorac Oncol 6: 372-7

[17] Hurwitz H, Fehrenbacher L, Novotny W, Cartwright T, Hainsworth J, Heim W, Berlin J, Baron A, Griffing S, Holmgren E, Ferrara N, Fyfe G, Rogers B, Ross R, Kabbinavar F (2004) Bevacizumab plus irinotecan, fluorouracil, and leucovorin for metastatic colorectal cancer. N Engl J Med 350: 2335-42 [18] Jain RK (1987) Transport of molecules in the tumor interstitium: a review. Cancer Res 47: 3039-51

[19] Judson I, Ma P, Peng B, Verweij J, Racine A, di Paola ED, van Glabbeke M, Dimitrijevic S, Scurr M, Dumez H, van Oosterom A (2005) 
Imatinib pharmacokinetics in patients with gastrointestinal stromal tumour: a retrospective population pharmacokinetic study over time. EORTC Soft Tissue and Bone Sarcoma Group. Cancer Chemother Pharmacol 55: 379-86

[20] Klosowska-Wardega A, Hasumi Y, Burmakin M, Ahgren A, Stuhr L, Moen I, Reed RK, Rubin K, Hellberg C, Heldin CH (2009) Combined antiangiogenic therapy targeting PDGF and VEGF receptors lowers the interstitial fluid pressure in a murine experimental carcinoma. PLoS One 4: e8149

[21] Larson RA, Druker BJ, Guilhot F, O'Brien SG, Riviere GJ, Krahnke T, Gathmann I, Wang Y (2008) Imatinib pharmacokinetics and its correlation with response and safety in chronic-phase chronic myeloid leukemia: a subanalysis of the IRIS study. Blood 111: 4022-8

[22] le Coutre P, Kreuzer KA, Pursche S, Bonin M, Leopold T, Baskaynak G, Dorken B, Ehninger G, Ottmann O, Jenke A, Bornhauser M, Schleyer E (2004) Pharmacokinetics and cellular uptake of imatinib and its main metabolite CGP74588. Cancer Chemother Pharmacol 53: 313-23

[23] Leveque D, Maloisel F (2005) Clinical pharmacokinetics of imatinib mesylate. In Vivo 19: 77-84

[24] Lindmark G, Sundberg C, Glimelius B, Pahlman L, Rubin K, Gerdin B (1993) Stromal expression of platelet-derived growth factor beta-receptor and platelet-derived growth factor B-chain in colorectal cancer. Lab Invest 69: 6829

[25] Matei D, Emerson RE, Schilder J, Menning N, Baldridge LA, Johnson CS, Breen T, McClean J, Stephens D, Whalen C, Sutton G (2008) Imatinib mesylate in combination with docetaxel for the treatment of patients with 
advanced, platinum-resistant ovarian cancer and primary peritoneal carcinomatosis : a Hoosier Oncology Group trial. Cancer 113: 723-32

[26] McArthur GA, Demetri GD, van Oosterom A, Heinrich MC, DebiecRychter M, Corless CL, Nikolova Z, Dimitrijevic S, Fletcher JA (2005) Molecular and clinical analysis of locally advanced dermatofibrosarcoma protuberans treated with imatinib: Imatinib Target Exploration Consortium Study B2225. J Clin Oncol 23: 866-73

[27] Messersmith WA, Jimeno A, Jacene $H$, Zhao M, Kulesza P, Laheru DA, Kahn Y, Spira A, Dancey J, lacobuzio-Donahue C, Donehower RC, Carducci M, Rudek MA, Hidalgo M (2010) Phase I trial of oxaliplatin, infusional 5-fluorouracil, and leucovorin (FOLFOX4) with erlotinib and bevacizumab in colorectal cancer. Clin Colorectal Cancer 9: 297-304

[28] Michael M, Gibbs P, Smith R, Godwood A, Oliver S, Tebbutt N (2009) Open-label phase I trial of vandetanib in combination with mFOLFOX6 in patients with advanced colorectal cancer. Invest New Drugs 27: 253-61

[29] Michael M, Vlahovic G, Khamly K, Pierce KJ, Guo F, Olszanski AJ (2010) Phase Ib study of CP-868,596, a PDGFR inhibitor, combined with docetaxel with or without axitinib, a VEGFR inhibitor. Br J Cancer 103: 155461

[30] Ogawa Y, Kawamura T, Furuhashi M, Tsukamoto K, Shimada S (2008) Improving chemotherapeutic drug penetration in melanoma by imatinib mesylate. J Dermatol Sci 51: 190-9

[31] Peng B, Dutreix C, Mehring G, Hayes MJ, Ben-Am M, Seiberling M, Pokorny R, Capdeville R, Lloyd P (2004) Absolute bioavailability of imatinib (Glivec) orally versus intravenous infusion. J Clin Pharmacol 44: 158-62 
[32] Peng B, Hayes M, Resta D, Racine-Poon A, Druker BJ, Talpaz M, Sawyers CL, Rosamilia M, Ford J, Lloyd P, Capdeville R (2004) Pharmacokinetics and pharmacodynamics of imatinib in a phase I trial with chronic myeloid leukemia patients. J Clin Oncol 22: 935-42

[33] Pietras K (2004) Increasing tumor uptake of anticancer drugs with imatinib. Semin Oncol 31: 18-23

[34] Pietras K, Ostman A, Sjoquist M, Buchdunger E, Reed RK, Heldin CH, Rubin K (2001) Inhibition of platelet-derived growth factor receptors reduces interstitial hypertension and increases transcapillary transport in tumors. Cancer Res 61: 2929-34

[35] Rodt SA, Ahlen K, Berg A, Rubin K, Reed RK (1996) A novel physiological function for platelet-derived growth factor-BB in rat dermis. $\mathrm{J}$ Physiol 495 ( Pt 1): 193-200

[36] Rutkowski P, Van Glabbeke M, Rankin CJ, Ruka W, Rubin BP, DebiecRychter M, Lazar A, Gelderblom H, Sciot R, Lopez-Terrada D, Hohenberger P, van Oosterom AT, Schuetze SM (2010) Imatinib mesylate in advanced dermatofibrosarcoma protuberans: pooled analysis of two phase II clinical trials. J Clin Oncol 28: 1772-9

[37] Safra T, Andreopoulou E, Levinson B, Borgato L, Pothuri B, Blank S, Tiersten A, Boyd L, Curtin J, Muggia F (2010) Weekly paclitaxel with intermittent imatinib mesylate (Gleevec): tolerance and activity in recurrent epithelial ovarian cancer. Anticancer Res 30: 3243-7

[38] Saharinen P, Alitalo K (2003) Double target for tumor mass destruction. J Clin Invest 111: 1277-80 
[39] Saltz LB, Clarke S, Diaz-Rubio E, Scheithauer W, Figer A, Wong R, Koski S, Lichinitser M, Yang TS, Rivera F, Couture F, Sirzen F, Cassidy J (2008) Bevacizumab in combination with oxaliplatin-based chemotherapy as first-line therapy in metastatic colorectal cancer: a randomized phase III study. J Clin Oncol 26: 2013-9

[40] Saraiya B, Karantza-Wadsworth V, Stein M, Chugh R, Mehnert J, Moss R, Lin Y, Poplin E (2009) Phase I study of gemcitabine, docetaxel, and imatinib in refractory and relapsed solid tumors. J Clin Oncol 27, (suppl; abstr e13538)

[41] Therasse P, Arbuck SG, Eisenhauer EA, Wanders J, Kaplan RS, Rubinstein L, Verweij J, Van Glabbeke M, van Oosterom AT, Christian MC, Gwyther SG (2000) New guidelines to evaluate the response to treatment in solid tumors. European Organization for Research and Treatment of Cancer, National Cancer Institute of the United States, National Cancer Institute of Canada. J Natl Cancer Inst 92: 205-16

[42] Vlahovic G, Rabbani ZN, Herndon JE, 2nd, Dewhirst MW, Vujaskovic Z (2006) Treatment with Imatinib in NSCLC is associated with decrease of phosphorylated PDGFR-beta and VEGF expression, decrease in interstitial fluid pressure and improvement of oxygenation. Br J Cancer 95: 1013-9 [43] von Wichert G, Hoehler T, Schimanski C, Moehler M, Hofheinz R, Kanzler S, Hinke A, Seufferlein T, Siebler J, Hochhaus A, Arnold D, Hallek M, Hacker UT (2011) Phase I/II trial of capecitabine (Cap) and oxaliplatin (Ox) in combination with bevacizumab (Bev) and imatinib (Ima) in patients with metastatic colorectal cancer (CRC): AlO KRK 0205. . J Clin Oncol 29: (suppl; abstr 3583) 
[44] Wang D, Huang HJ, Kazlauskas A, Cavenee WK (1999) Induction of vascular endothelial growth factor expression in endothelial cells by plateletderived growth factor through the activation of phosphatidylinositol 3-kinase. Cancer Res 59: 1464-72

[45] Yardley DA, Burris HA, 3rd, Markus T, Spigel DR, Greco FA, Mainwaring M, Waterhouse DM, Webb CD, Hainsworth JD (2009) Phase II trial of docetaxal plus imatinib mesylate in the treatment of patients with metastatic breast cancer. Clin Breast Cancer 9: 237-42 